NICOLÁS PEDRO GUIDI

\title{
«FIJANDO LA MIRADA EN EL AUTOR Y PERFECCIONADOR DE LA FE, JESÚS»
}

Aproximación a Heb 12,1-3

\section{Introducción}

Ya estamos mediando el «Año de la fe» que el papa Benedicto XVI ha inaugurado el pasado mes de octubre. Con esta propuesta ha invitado a toda la Iglesia a «intensificar la reflexión sobre la fe para ayudar a todos los creyentes en Cristo a que su adhesión al Evangelio sea más consciente y vigorosa, sobre todo en un momento de profundo cambio como el que la humanidad está viviendo» ${ }^{1}$. En sintonía con este contexto eclesial se encuadra el aporte bíblico-teológico que proponemos sobre el pasaje de Heb 12, 1-3. En efecto, la afirmación central de estos versículos es la citada por el Santo Padre en la carta apostólica Porta fidei como línea-guía para este año: «Durante este tiempo tendremos la mirada fija en Jesucristo, "que inició y completa nuestra fe" (Heb 12,2): en él encuentra su cumplimiento todo afán y todo anhelo del corazón humano» ${ }^{2}$. Nos ha parecido oportuno profundizar sobre los alcances de esta novedosa confesión de fe neotestamentaria, original de la carta a los Hebreos, ya que en ella se expresa de un modo admirable la íntima conexión entre la fe del creyente y aquel que es su origen y perfección. En primer lugar nos concentraremos en los aspectos gramaticales del texto, en su estructura y género literario, para ofrecer, luego del comentario exegético, una relación entre los aspectos cristológicos presentes en el texto y la cristología de toda la carta a los Hebreos.

1 Benedicto XVI, Carta apostólica «Porta fidei», 8.

2 Ibíd., 13. 


\section{Texto y análisis gramatical}

El texto referido forma parte de una perícopa más extensa que abarca los vv. 1-13 del cap. 12 de la carta a los Hebreos; sin embargo, solamente nos detendremos a considerar los primeros tres versículos, que entre sí forman una microunidad dentro de la perícopa. Ofrecemos a continuación el texto en griego ${ }^{3}$ y su traducción:

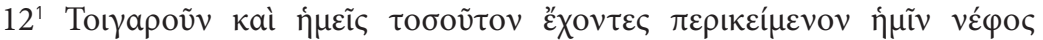

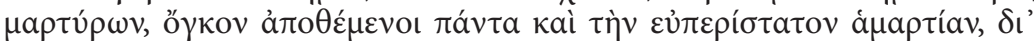

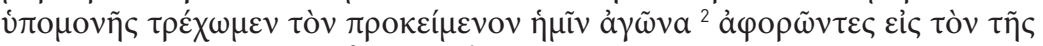

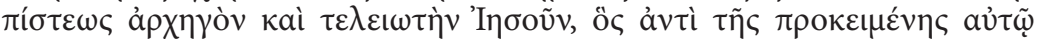

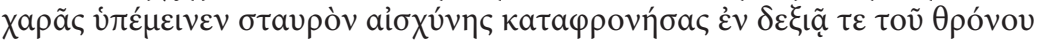

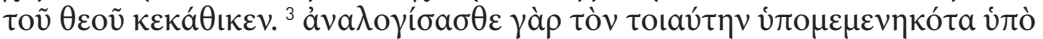

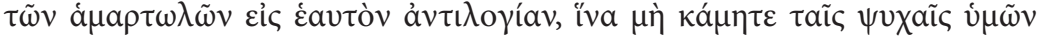
$\dot{\varepsilon} \kappa \lambda \nu o ́ \mu \varepsilon v o t$.

$12^{1}$ Así pues, también nosotros, teniendo en torno nuestro tan gran nube de testigos, habiéndonos despojado de toda carga y del pecado que nos asedia, corramos con paciencia la carrera que se nos propone, ${ }^{2}$ fijando los ojos en el iniciador y perfeccionador de la fe, Jesús, quien frente al gozo que se le proponía soportó con paciencia la cruz, despreciando la vergüenza, y se ha sentado a la derecha del trono de Dios. ${ }^{3}$ Consideren, pues, a aquel que ha soportado tal contradicción contra sí por parte de los pecadores, para que no se fatiguen, faltos de ánimo.

- v. 1. En cuanto a la estructura gramatical, los dos primeros versículos constituyen una sola frase con un verbo principal y su objeto: $\tau \rho \varepsilon ́ \chi \omega \mu \varepsilon v$ tòv ả $\gamma \tilde{\omega} v a$ («corramos la carrera»). El resto de la larga oración se compone de frases de participio, frases preposicionales, aposiciones, subordinadas y

${ }^{3}$ A nivel de crítica textual, la única variante de relevancia se encuentra en el v. 3 y afecta a las palabras દic દ́avtóv. Se produce una difícil elección debido a que importantes testigos presentan distintas lecturas. Por un lado, $\boldsymbol{\aleph}^{*}$, D* y la versión si-

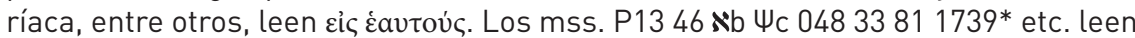

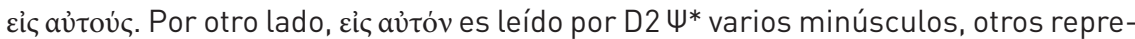
sentantes de la recepción bizantina, etc.; y દic દ̇avtóv es atestiguado por A P 0150, algunos minúsculos y versiones. Finalmente, otros testigos de menor importancia la traducen más libremente o directamente la omiten. Si bien la evidencia externa se inclina hacia alguna de las dos primeras opciones, es decir, en plural, y desde los criterios internos podemos decir que cualquiera de ambas sería más propiamente la lectio difficilior, sin embargo coincidimos con la edición crítica de Nestle-

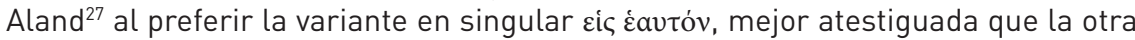
singular al ser presentada por el uncial alejandrino, dado que en plural la frase tiene muy poco sentido y no se ve el modo de traducirla satisfactoriamente. 
oraciones de relativo. Este verbo principal está en subjuntivo exhortativo y marca el carácter parenético de toda la perícopa. El primer participio que de

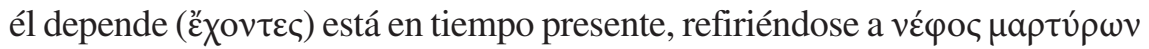
(«nube de testigos»). El segundo es un participio aoristo, ả $\pi 0 \theta \varepsilon ́ \mu \varepsilon v o l, q u e$, según algunos autores, es mejor traducirlo como un verbo activo atendiendo a un posible matiz exhortativo («despojémonos», «sacudamos») en sintonía con el verbo principal. Sin embargo, preferimos reflejar en la traducción su carácter de participio («habiéndonos despojado») y su dependencia respecto de $\tau \rho \varepsilon ́ \chi \omega \mu \varepsilon v$. El objeto de este participio es doble y hace referencia a la ca-

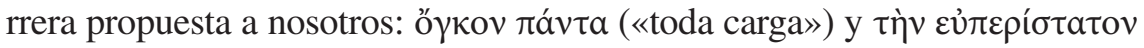

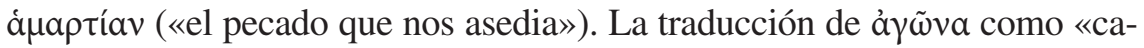

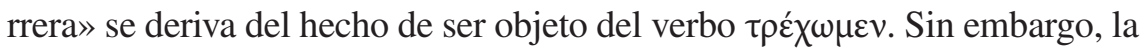
palabra, más que «carrera» significa «lucha» o «combate», «certamen», «competencia»; de hecho se refiere también al lugar donde se realizaban las

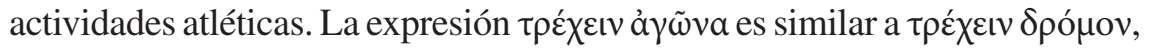
que es utilizada en la literatura paulina (1 Cor 9,24; Gál 2,2; Flp 2,16). Y, aunque la traducción no lo manifieste, la expresión griega conserva el matiz de oposición o lucha propia de la «carrera» cristiana.

- v. 2. El participio ả $\varphi$ o $\tilde{\omega} \nu \tau \varepsilon \varepsilon \varsigma$ («fijando la mirada») en tiempo presente manifiesta una concomitancia temporal con el verbo principal $\tau \rho \varepsilon ́ \chi \omega \mu \varepsilon v$. La expresión siguiente condensa admirablemente la cristología

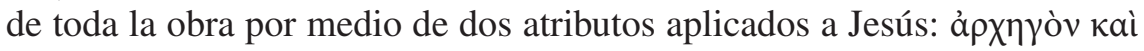

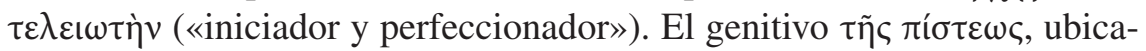
do inmediatamente antes del primero, no solo modifica a este, sino a ambos adjetivos. Continúa con una construcción de relativo referida a Jesús.

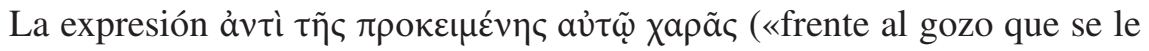
proponía») es susceptible de dos sentidos en torno a la preposición ảvti: uno final, «en vistas al gozo...», tal vez haciendo referencia a la propia glorificación; otro sustitutivo, «en lugar del gozo...», aludiendo al despojo de la encarnación y la cruz (Flp 2,6ss). Uno subraya el resultado final; otro, la fortaleza de la elección. La traducción «frente a» que hemos adoptado respeta ambos matices sin excluir ninguno de los dos. El participio presente $\pi \rho о \kappa \varepsilon \mu \varepsilon ́ v \eta \varsigma$ indica una posibilidad actual más que futura. Los dos verbos principales de esta proposición están el primero en aoristo -ijé $\mu \varepsilon ı v \varepsilon v$

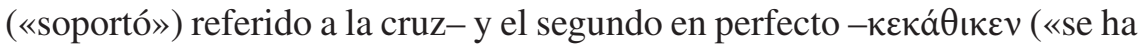
sentado») referido a la entronización a la derecha del Padre-, marcando con esta distinción la durabilidad y permanencia del estado glorioso de Cristo en el momento presente.

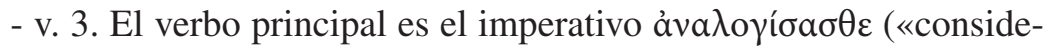

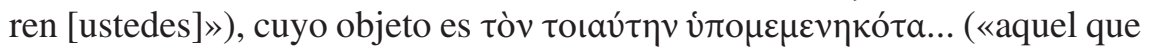




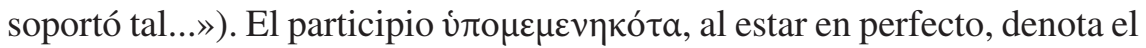
efecto durativo de los sufrimientos de Jesús y la vigencia de su ejemplo,

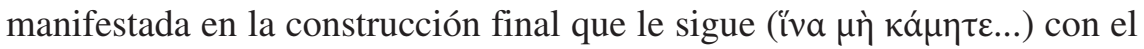
verbo en aoristo subjuntivo.

\section{Estructura y géneros literarios}

Los vv. 1-3 constituyen la introducción del tema principal de la perícopa $(12,1-13)$ y a la vez la base de todo el desarrollo posterior sobre la corrección ( $\pi \alpha ı \delta \varepsilon i ́ \alpha)$ divina (vv. 4-11), que se debe soportar con paciencia a ejemplo de Jesús. Estos versículos constituyen una microunidad de carácter marcadamente cristológico cuyo centro está en 2a. No es sencillo describir una estructura dentro de esta subdivisión dado que hay una trabazón muy estrecha entre los elementos que la componen. Vanhoye ${ }^{4}$ habla de una disposición concéntrica que compara simétricamente la situación de Cristo con la de los cristianos, pero la descripción que realiza no deja en claro una estructura bien definida. V. Rhee ${ }^{5}$ propone una organización quiásmica que involucra a los tres versículos, aunque la correspondencia entre los distintos segmentos no es del todo convincente, sobre todo en lo que respecta a la relación entre 1 y 3 . De acuerdo a nuestro parecer, el quiasmo comprende solo 1-2, según se muestra a continuación ${ }^{6}$ :

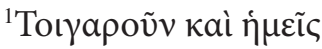

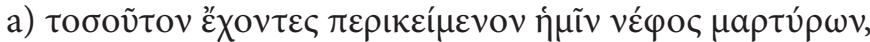

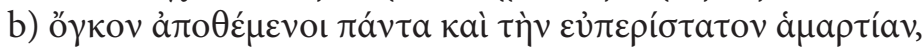

c) $\delta \imath^{\prime} \dot{v} \pi \circ \mu \nu v \tilde{\eta} \varsigma \tau \rho \varepsilon ́ \chi \omega \mu \varepsilon v$

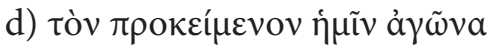

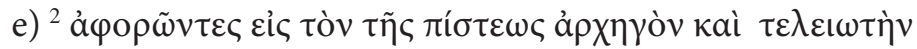
'Inбoṽv,

${ }^{4}$ A. Vanhoye, La structure littérarie de l'épitre aux Hébreux. Paris, Desclée de Bouwer, ${ }^{21973, ~ p p . ~ 197-198 . ~}$

5 V. RHEE, «Chiasm and the concept of faith in Hebrews 12:1», en Westminster Theological Journal 63 (2001), pp. 270-272.

6 Esta postura es también asumida y propuesta por C. Marcheselli-CASAle, Lettera agli Ebrei. Milano, Paoline, 2005, pp. 545-547; E. HoRnING, «Chiasmus, creedal structure, and christology in Hebrews 12:1-2», en Biblical Research 23 (1978), pp. 40-42; D. BLACK, «A note on the structure of Hebrews 12,1-2», en Biblica 68 (1987), pp. 543-551; R. MAN «The Value of Chiasm for New Testament Interpretation», en Bibliotheca Sacra 141 (1984), p. 149. 


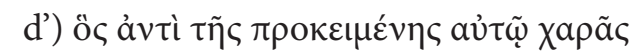

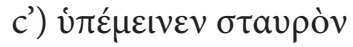

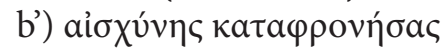

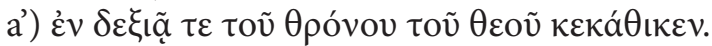

Así pues, también nosotros

a) teniendo en torno nuestro tan gran nube de testigos

b) habiéndonos despojado de toda carga y del pecado que nos asedia,

c) corramos con paciencia

d) la carrera que se nos propone,

e) fijando los ojos en el iniciador y perfeccionador de la fe, Jesús,

d') quien, frente al gozo que se le proponía,

c') soportó con paciencia la cruz,

b') despreciando la vergüenza,

a') y se ha sentado a la derecha del trono de Dios.

De este modo se ve que el centro de la estructura está ocupado por 2a y que a partir de allí se organiza una simetría entre las partes. Las líneas d y d' tienen en común la utilización del mismo participio presente pasivo

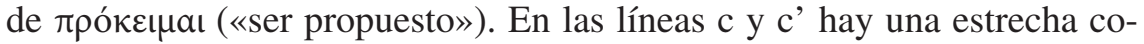

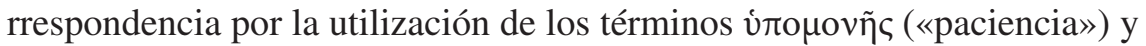

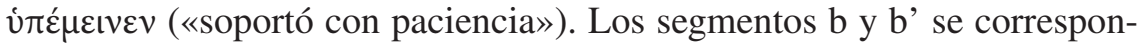
den no por la utilización de términos emparentados, sino por una relación

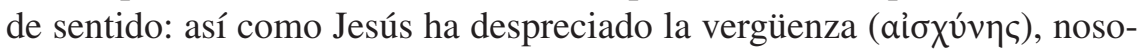

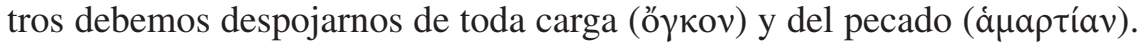
Finalmente, a y a' se relacionan, aunque de una manera bastante menos explícita, por medio de la descripción del estado de los testigos, que están en torno nuestro $\left(\pi \varepsilon \rho \varepsilon^{\prime} \varepsilon_{\mu \varepsilon v o v}{ }^{7}\right.$, y el de Jesús, que se ha sentado a la derecha

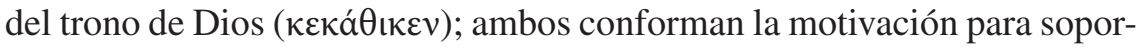
tar pacientemente y correr la carrera propuesta.

El centro del quiasmo es siempre el punto de inflexión; allí hay un cambio de tendencia, de pensamiento o una idea antitética. Idénticas palabras o ideas se distribuyen desde el centro, y los nombres divinos o los títulos tienden a gravitar en el punto central ${ }^{8}$. En nuestro caso, la línea principal

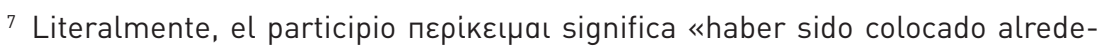
dor». Cf. M. Zerwick / M. Grosvenor, Análisis gramatical del griego del Nuevo Testamento. Estella, Verbo Divino, 2008, p. 802.

8 Cf. E. Horning, «Chiasmus, creedal structure, and christology in Hebrews 12:1-2», a. c., pp. 40-42. 
constituye una confesión de fe en Jesús, a quien se le atribuyen dos títulos muy particulares que encierran una riqueza de sentido muy profunda porque asumen y resumen la doctrina cristológica expuesta a lo largo de todo el sermón. Los títulos son ả $\rho \chi \eta \gamma o ́ \varsigma$ (iniciador, autor, pionero, fundador) y $\tau \varepsilon \lambda \varepsilon เ \omega \tau \eta \dot{\varsigma}$ (perfeccionador, consumador), referidos a la fe ( $\pi i ́ \sigma \tau \iota \varsigma)$. Ahondaremos más adelante sobre el alcance de estos términos.

A su vez, el v. 2a se puede ver como el punto de partida del fragmento hímnico cristológico que constituye $2 \mathrm{bc}$. El pronombre relativo ọ̈ («el cual», en referencia a Jesús) concatena a ambos y es utilizado con frecuencia en las fórmulas de fe. Internamente presenta un esquema típico de las mismas: descenso-muerte-ascensión-entronización. Por medio de este trabajo de ensamblar ambos elementos, el autor ofrece una relación entre la figura y el ejemplo de Jesús y la actitud que debemos imitar de él los cristianos.

El v. 3: "Consideren, pues, a aquel que ha soportado tal contradicción contra sí por parte de los pecadores, para que no se fatiguen, decayéndose en sus almas», se vincula a la microunidad 1-2, pero conserva una cierta independencia, ya que en 3 a se relanza con más fuerza la ex-

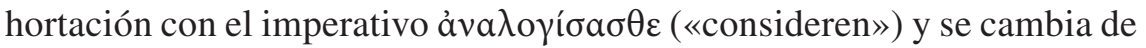
primera a segunda persona del plural. Este verbo remite al participio de 2a: $\dot{\alpha} \varphi о \rho \tilde{\omega} v \tau \varepsilon \varsigma$ («fijando los ojos»), pero relanzándolo de forma directa a los oyentes. Utilizando la conjunción үà $\rho$ («pues», «entonces») infiere de lo anterior una consecuencia para la imitación de los creyentes. Se

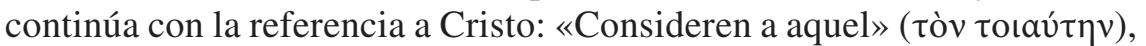
como modelo de paciencia ( $\dot{\pi} \tau \mu \varepsilon \mu \varepsilon v \eta \kappa o ́ \tau \alpha)$. Se retoma la idea de anta-

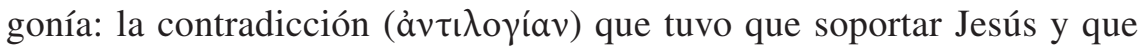
está en contacto con el combate/carrera $(\dot{\alpha} \gamma \tilde{\omega} v)^{9}$ que es propuesto para los cristianos en el v. 1. A su vez, tanto en vv. 1-2 como en v. 3 se evidencia que la resistencia u oposición proviene del pecado: áuaptíav (v. 1) con $\alpha \dot{\alpha} \alpha \rho \tau \omega \lambda \tilde{\omega} v$, «pecadores» (v. 3). Por último, la construcción final, encabezada por la preposición îva, concluye este versículo y cierra el parágrafo 1-3 con los motivos o razones por las cuales los cristianos deben considerar el ejemplo de paciencia dado por Cristo: no fatigarse ni desfallecer faltos de ánimo.

En cuanto al género literario, es de particular importancia el v. 2, en el cual algunos autores reconocen claramente elementos propios de una homo-

9 El matiz de oposición se ve con mayor claridad en griego. En nuestra traducción optamos por «carrera» en vez de «combate» o «lucha», ya que el verbo $\tau \rho \varepsilon ́ \chi \omega \mu \varepsilon v$ («corramos») exige más bien esa opción, pero queda en menor evidencia la dimensión de antagonía que es propia de ese término. 
logía, himno o fórmula de $\mathrm{fe}^{10}$. Por ejemplo, se inicia con el característico pronombre relativo ôc, empleado aquí al igual que en otros himnos cristológicos del NT (Flp 2,6; Col 1,15; 1 Tim 3,16; Ef 2,14), precedido de una alabanza o una referencia a Cristo como Señor o con algún otro título: en 12,2 es la apo-

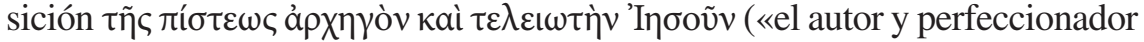
de la fe, Jesús»). Estilísticamente, las composiciones de este tipo están a favor de la antítesis: en nuestro verso nos encontramos con los contrastes de la entronización y de la alegría frente a la cruz y la vergüenza (también así en Flp 2,6-11; 1 Pe 3,18-20; Rom 4,25). El ritmo y la estructura formal se manifiestan por medio de un quiasmo con paralelismo de palabras e ideas:

a. quien frente al gozo que se le proponía

b. soportó la cruz,

$b$ '. despreciando la vergüienza,

$a^{\prime}$. y se ha sentado a la derecha del trono de Dios.

Es característico el tipo de contenido cristológico que utiliza, ya que expone los temas y frases que se encuentran en otros credos e himnos:

a. Jesús desciende de la gloria del cielo:

Heb 12,2: «Frente al gozo que se le proponía».

Flp 2,6: «Siendo de condición divina, no retuvo para sí su igualdad con Dios».

Jn 1,9: «La luz verdadera que ilumina a todo hombre estaba viniendo al mundo».

b. Muere:

Heb 12,2: «Soportó la cruz».

Flp 2,8: «Obedeciendo hasta la muerte».

Col 1,18: «El primogénito de entre los muertos».

1 Pe 3,18: «Murió una sola vez por los pecados».

c. Su muerte es ignominiosa:

Heb 12,2: «Despreciando la vergüenza».

Flp 2,8: «Y se humilló a sí mismo, obedeciendo hasta la muerte, y muerte de cruz».

10 E. Horning, «Chiasmus, creedal structure, and christology in Hebrews 12:12», a. c., pp. 39-40; W. GLoER, «Homologies and hymns in the New Testament: form, content and criteria for identification», en Perspectives in Religious Studies 11 (1984), pp. 115-132; J. SANDERS, The New Testaments Christologically Hymns. Cambridge, University Press, 1971, pp. 19-20; D. BLACK, «A note on the structure of Hebrews 12,1-2», a. c., pp. 543-551. 
d. Es exaltado y entronizado en la gloria:

Heb 12,2: «Y se ha sentado a la derecha del trono de Dios».

Flp 2,9: «Por lo cual Dios le exaltó y le otorgó el Nombre, que está sobre todo nombre».

$1 \operatorname{Tim}$ 3,16: «Levantado a la gloria».

1 Pe 3,22: «Habiendo ido al cielo, está a la diestra de Dios».

Dada la brevedad del versículo, puede no ser tan clara la identificación con un himno a la misma altura de otros del NT en donde estos elementos se ven con mayor claridad; pero no se pueden dejar de reconocer allí la presencia de componentes esenciales que forman parte de los mismos. Esto no quiere decir que el autor haya incorporado un himno o confesión cristológica que ya se transmitía tal cual él la propone. La aceptación de un pasaje como preformulado no indica que no fuera escrito por el autor de la obra en la que se encuentra. Puede representar una fórmula elaborada por el autor anteriormente y que se incluye en la obra debido a su importancia para el asunto que se está tratando. La capacidad creativa de un escritor debe ser reconocida y respetada. Siempre es posible que un autor pueda producir material poético que posea características de un himno u homología ${ }^{11}$. La utilización de una composición de este tipo hace al texto más estilísticamente atractivo y lo provee de un alto grado de impacto emocional en los oyentes, razón por la cual se explica su incorporación en nuestra perícopa, ya que en esta el autor busca motivar con el ejemplo de Jesús la perseverancia en la fe de los destinatarios.

\section{Comentario exegético}

El autor inicia una nueva sección de su sermón con una interpelación directa a los oyentes en la cual se vincula también él mismo (primera persona del plural). El tema que comienza a desarrollar es consecuencia de lo expuesto anteriormente; así lo demuestra por medio de la conjunción consecutiva tolyapoũv, como si de lo anterior se infiriera necesariamente lo que viene a continuación. De hecho, el capítulo 11 entero es una alabanza a los antiguos por la fe que tuvieron y que los mantuvo firmes en las pruebas. Aun así no consiguieron la promesa que nosotros podemos alcanzar (cf. 11,39-40). La referencia a la nube de testigos ${ }^{12}$ pone en estrecha vincu-

11 Cf. W. GloER, «Homologies and hymns in the New Testament: form, content and criteria for identification», a. c., p. 130.

12 La palabra vé $\varphi$ oc («nube») no parece tener otro sentido más que el sentido metafórico de «multitud». 
lación con los numerosos personajes ejemplares mencionados en ese capítulo: se refiere a ellos en 11,39 como $\mu \alpha \rho \tau \nu \rho \eta \theta \dot{\varepsilon} v \tau \varepsilon \varsigma$, y en 12,1 como

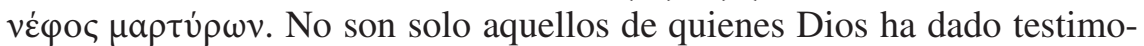
nio, sino que también son los que van a dar testimonio de nuestra carrera de

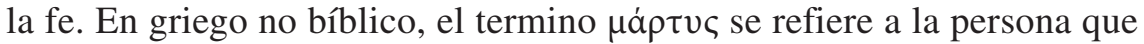
da testimonio en un juicio, describe lo que ha visto o verifica lo que otro ha dicho. La LXX, por lo general, se refiere a Dios como aquel que da testimonio, y en este sentido es usado también numerosas veces en Heb (11,2.4.5.39). Sin embargo, en 12,1, la palabra recibe un giro ligeramente diferente. No está claro si el autor quiere decir que los fieles son testigos de nuestra fe o si son testigos de la validez de la fe a causa de los sufrimientos que soportaron. Sería un error considerarlos únicamente como testigos pasivos, al modo de los espectadores de los anfiteatros griegos ${ }^{13}$. La ambivalencia deja abierta ambas interpretaciones, que son complementarias, y prepara el camino para el uso posterior del término en la Iglesia: $\mu a ́ \rho \tau v \varsigma$ aún no se había convertido en un término técnico para los que mueren por la fe, pero su uso aquí parece estar en camino de la comprensión de la palabra $^{14}$.

La presencia de los testigos debe ser un fuerte estímulo para la carrera que se nos propone. La metáfora atlética refuerza el sentido de lucha y esfuerzo que implica la vida cristiana, pero no solo en un sentido moral (a semejanza del uso estoico de la misma), sino también desde una dimensión escatológica, ya que indica la meta a la que debemos aspirar (cf. 11,40; 12,2.9.11). Para ello es preciso despojarse de todo lo que perturba y nos retrasa en el certamen ${ }^{15}$.

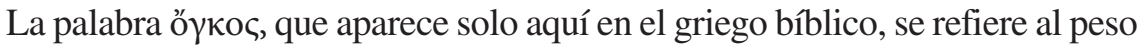
o a la carga de la que es preciso librarse para la carrera. En la literatura extrabíblica, su uso metafórico se refiere con frecuencia al orgullo, aunque también puede aplicarse al «amor a las riquezas, al apego al mundo, a las preocu-

$13 \mathrm{~S}$. BAUGH, «The cloud of witnesses in Hebrews $11 »$, en Westminter Theological Journal 68 (2006), pp. 113-132, analiza la expresión en Heb 11 y concluye que es errónea esa interpretación. Algunos autores la han propuesto derivándola de la metáfora atlética, que es aludida por la «carrera», y de la expresión «en torno nuestro» como si fuera la disposición de un anfiteatro. Pero del contexto se infiere mejor una interpretación más «activa» del término.

14 Cf. E. Horning, «Chiasmus, creedal structure, and christology in Hebrews 12:1-2», a. c., p. 41. Una interesante y original interpretación de la expresión vé $\varphi \omega \varsigma$

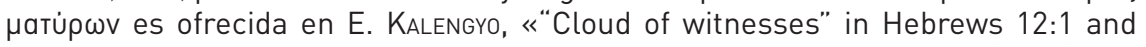
Ganda ancestors: an incarnational reflection», en Neotestamentica 43 (2009), pp. 49-68, donde realiza una comparación de la misma con el papel que juegan los antepasados en la vida de los vivos, según las creencias tradicionales en Ganda.

15 Cf. 1 Cor 9,25; Gál 2,2; 2 Tim 4,7; Flp 2,16. 
paciones y a los intereses terrenos, etc.» ${ }^{16}$. En paralelo a esa palabra, el autor

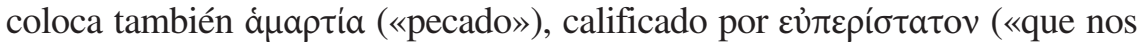
asedia» ${ }^{17}$, es decir, que nos perturba y dificulta avanzar. No parece referirse al pecado de apostasía, según proponen algunos autores, ni tampoco exclusivamente al pecado del desánimo ${ }^{18}$, sino más bien al pecado en general como obstáculo y fuerza que se opone a Cristo (cf. 3,$13 ; 12,4$ ).

Como ya notamos, el verbo principal y único de los dos primeros versículos es $\tau \rho \varepsilon ́ \chi \omega \mu \varepsilon v$ («corramos»). Pero no se debe correr de cualquier modo,

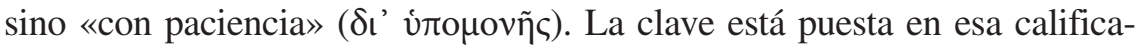
ción ${ }^{19}$. El término determina el sentido de la perícopa, según fue anunciado en 10,36: «[Ustedes] tienen necesidad de paciencia para que, cumpliendo la voluntad de Dios, consigan la promesa» ${ }^{20}$. Fundamentalmente «significa -en sentido positivo- la acción de permanecer firme por los propios medios, de manera inflexible y obstinada, frente a los males que acosan, y se refiere a una forma de valentía; en sentido negativo significa el ignominioso aguante de las humillaciones» ${ }^{21}$. Se puede ver una concurrencia de este vocablo en 4 Mac, utilizado allí para referirse a la actitud de los mártires ${ }^{22}$.

16 G. Mora, La carta a los Hebreos como escrito pastoral. Barcelona, Herder, 1974, p. 82

17 Un adjetivo en caso acusativo que significa «que aqueja o perturba con facilidad», también es un término que hace referencia a algo que ejerce un control estricto sobre otra cosa, que domina. Cf. H. LIDELL / R. ScotT (comps.), A Greek-English Lexicon. Oxford, Clarendon Press, 1996, p. 726; H. BALz / G. SCHNEIDER (dirs.), Diccionario exegético del Nuevo Testamento. Salamanca, Sígueme, 1996, p. 1674; C. SPICQ, Theological Lexicon of the New Testament. Massachusetts, Hendrickson, 2008, pp.

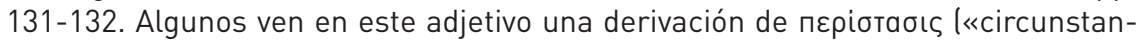

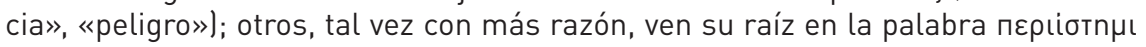
[«poner en derredor», «oprimir»).

18 C. SPIcQ, Theological Lexicon of the New Testament, o. c., p. 385; G. Mora, La carta a los Hebreos como escrito pastoral, o. c., pp. 82-83. Puede referirse a la fatiga o al desánimo, según sugiere el contexto atlético, aunque no parece ser excluyente. Esta interpretación puede ser apoyada por la mención del pecado en el v. 3, donde el autor realiza una marcada paráclesis que determina la finalidad de la perseverancia: «Para que no se fatiguen, faltos de ánimo».

19 G. Mora, La carta a los Hebreos como escrito pastoral, o. c., p. 81, la llama «palabra vedette» de todo el párrafo (12,1.2.3), especialmente en 12,1, acentuada por su posición.

20 También cf. 10,32-34.

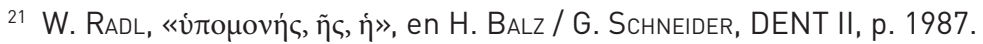

22 Por ejemplo, en $4 \mathrm{Mac}$ 6, 9 se describe la actitud del anciano Eleazar con una

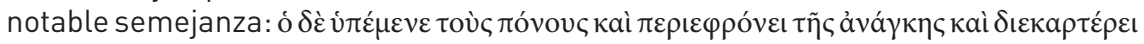

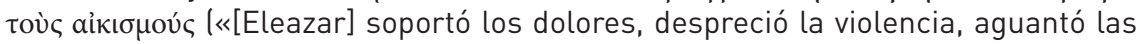


Si bien el ejemplo de los antiguos significa para los cristianos un estímulo importante, el punto capital de la exhortación lo constituye el ejemplo de paciencia manifestado en Jesús. Los cristianos deben correr teniendo fija la mirada en él. Pero, más aún, su obra no es solo algo ejemplar para imitar: debemos poner la mirada en él porque es el «iniciador y perfeccio-

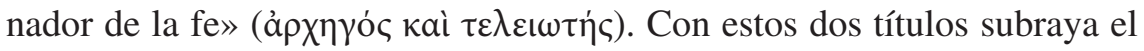
lugar único de Cristo y de su obra salvífica respecto de la comunidad. No puede ser comparado ni puesto en el nivel del ejemplo de los antepasados. Por medio de la pasión, que soportó con paciencia, y de su entronización a la derecha del trono de Dios, él nos hace posible la constancia en la carrera y la llegada a la meta. Los dos títulos indican un arco que se abre desde el inicio hasta la consumación, y ninguna otra persona más que Jesús se encuentra en esta posición ${ }^{23}$.

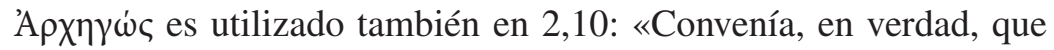
aquel por quien es todo y para quien es todo, llevara muchos hijos a la gloria, perfeccionando [ $\tau \varepsilon \lambda \varepsilon \mid \tilde{\omega} \sigma a l]$ mediante el sufrimiento al que iba a guiarlos [ả $\chi \eta \gamma o ̀ v]$ a la salvación». Allí también es puesto en relación con el

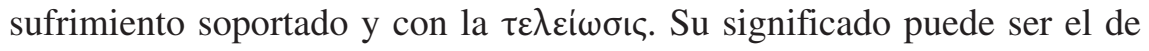
«pionero», «caudillo» o «guía», pero también el de «autor», «iniciador», «aquel que abre el camino». Esta segunda serie es más propia para nuestro texto porque se entiende que Cristo es el que nos precede, quien entra como precursor en el santuario del cielo $(6,20)$, quien por su sacrificio de obediencia a través del sufrimiento $(2,10)$ es capaz de conducirnos a la gloria. La fe ( $\pi i \sigma \tau \iota \varsigma)$ no se atribuye a Jesús como se le puede atribuir a un simple creyente (por eso conviene mejor traducir «autor»o «iniciador» en lugar de «pionero» $\mathrm{o}$ «caudillo»).

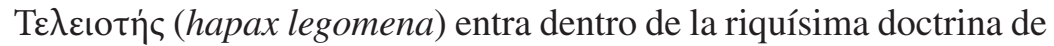
la perfección que ofrece el autor de Heb aplicada a Jesús. Él es el sumo sacerdote hecho perfecto y capaz de perfeccionar a los que por él se acercan a Dios $(7,25)^{24}$. El pasaje no busca presentarnos como ejemplar la fe de Je-

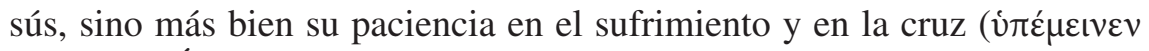

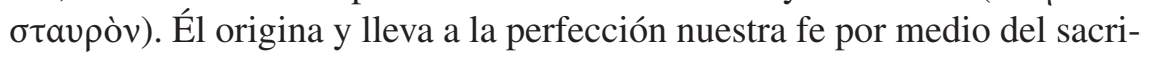

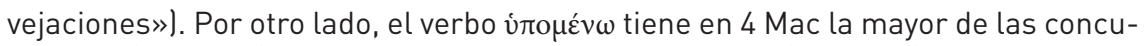
rrencias (15 veces), lo mismo que el sustantivo írouoví (11 veces), más que cualquier otro escrito del AT.

${ }^{23}$ Cf. A. VANHOYE, «La fede di Gesù? A proposito di Ebrei 12,2: "Gesù, autore e perfezionatore della fede"», en Pontificia Accademia Theologica (2003), p. 415.

${ }^{24}$ A. Vanhore, Sacerdotes antiguos, sacerdote nuevo. Salamanca, Sígueme, ${ }^{4} 2002$, pp. $177-180$. 
ficio de la cruz ${ }^{25}$. El breve himno cristológico del v. 2ce remarca esta afirmación describiendo el proceso personal de Jesús, que sí es modélico para los cristianos. Allí aparece por primera vez la oposición alegría/sufrimiento, que luego será retomada en relación con la disciplina (v. 11). Jesús, frente a la alegría propuesta, soporta la cruz y desprecia la vergüenza, así como el cristiano debe también pasar por la tristeza pasajera (v. 11) soportando la corrección (v. 7) y despojándose de todo lo que estorba (v. 1). Hemos notado ya la dificultad al traducir la preposición ảvtí, que en este contexto puede tener dos sentidos: «en lugar de» o «en vistas a» la alegría propuesta. En torno a este dilema se han suscitado interesantes estudios que ya mencionamos. Ambas son posibles y a la vez complementarias. La primera se refiere a que Cristo renunció a su derecho de ser tratado como Dios (en la línea de Flp 2,6-8); la segunda alude a la recompensa de la gloria que recibiría después de la muerte (recompensa que es propuesta también a los cristianos en varios pasajes de Heb, especialmente en 10,35$)^{26}$. Por eso nosotros optamos por conservar la ambivalencia utilizando la expresión «frente a». El v. 2 contiene la única mención explícita de la cruz. No se refiere a ella en un sentido metafórico ${ }^{27}$, sino al acontecimiento del Calvario, como en el himno cristológico de Flp 2,7.

Allí también sobresale la contraposición del binomio «vergüenzagloria», característico del movimiento descendente-ascendente de este tipo de himnos referidos a Cristo. Él desprecia la vergüenza y luego está senta-

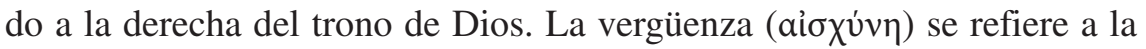
muerte ignominiosa de la cruz $^{28}$. Jesús desprecia la gloria y el honor humano en vistas a no perder el verdadero honor, que es el que brota de la obediencia a Dios ${ }^{29}$. La recompensa es la entronización que revierte la situación de deshonor humano con la glorificación junto a $\operatorname{Dios}^{30}$, situación que

25 A. VANHOYE, «La fede di Gesù?...», a. c., pp. 414-415.

26 A. VAnhoye, L'epistola agli Ebrei. Bologna, Ed. Dehoniane, 2010, p. 271.

27 Como puede observarse, por ejemplo, en Gál 6,12.14 o en Mc 8,34 //.

28 De un modo similar utiliza la palabra ỏveı $\delta$ เoús en 10,$33 ; 11,26 ; 13,13$.

29 Cf. D. DeSILVA, «Despising Shame: A Cultural-Anthropological Investigation of the Epistle to the Hebrews», en Journal of Biblical Literature 113 (1994), p. 459.

30 La exaltación gloriosa de Jesús, luego de haber soportado la cruz, se expresa con la noción de entronización basada en Sal 110,1. Este salmo juega un papel importantísimo en el desarrollo de toda la obra desde sus primeros capítulos. Heb es el escrito del NT que más lo cita. La expresión retomada aquí reafirma un tema anunciado formalmente en 1,3 y elaborado en $2,5-9$ y $10,12-13$, y que en 8,1 se pone como parte del argumento central: «Este es el punto capital de cuanto venimos diciendo, que tenemos un Sumo Sacerdote tal que se sentó a la diestra del trono de 
se convierte en el verdadero estímulo para el creyente y meta de la carrera propuesta.

El v. 3 vuelve sobre la exhortación a considerar el ejemplo de Cristo para no decaer ni desanimarse. Pero aquí no habla de la entronización glorio-

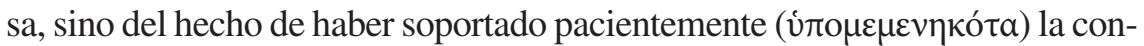
tradicción y la oposición de los pecadores; el tema de la recompensa será expuesto luego (vv. 9-11). Hay que destacar dos elementos: en primer lugar se

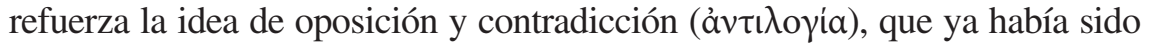
mencionada en el v. 1 con el empleo de la palabra á $\gamma \omega \dot{v} v$, que si bien nosotros

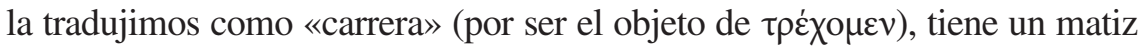
de competición y combate. Aquí es la fuerza hostil de los pecadores que se oponen a Jesús. Puede ser que el autor tenga en mente la recurrente imagen de los salmos, en donde se describe la saña de los impíos en contra del justo ${ }^{31}$. Son también las palabras de Jesús en Mc 14,41 antes de ser arrestado: «Ha llegado la hora en que el Hijo del hombre va a ser entregado en manos de los pecadores». En segundo lugar se introduce el tema del desánimo y del desfallecimiento ( $\dot{\varepsilon} \kappa \lambda \dot{o} \circ \mu a$ ), que anticipa el mandato de Proverbios que luego va a citar, «no te decaigas» ( $\mu \eta \delta \dot{\varepsilon} \dot{\varepsilon} \kappa \lambda \dot{v}$ ov), y que en los vv. 12-13 va a relanzar nuevamente invitando a fortalecer las manos caídas y las rodillas que han flaqueado. La insistencia en este segundo punto parece indicarnos algo de la situación vital de la comunidad destinataria, amenazada por «la fatiga, el descorazonamiento en la larga carrera tras Jesús, la pérdida de la ilusión inicial, que se les adhiere como pesado vestido y amenaza con imposibilitarles la constancia de su fe, momento esencial en la participación de Cristo $(3,14) »^{32}$.

la Majestad en los cielos». Ya hemos mencionado anteriormente que esta expresión parece formar parte de los primeros himnos cristológicos formulados con el doble movimiento «descenso-elevación». Y que con mucha probabilidad, anteriormente a la redacción de Heb, el Salmo 110 era releído en clave cristológica, presentando la glorificación de Cristo como la entronización a la derecha de Dios, según la expresión del v. 1. El sentarse a la derecha es puesto como contrapunto con la cruz y la muerte de Jesús, mostrando una reversión de la situación de humillación; es como una recompensa por haber soportado la prueba y aceptado la cruz frente al gozo que se le proponía. Podemos concluir que Heb 12,2 utiliza el tema de «sentarse a la derecha» en dos direcciones diferentes: por un lado, en una línea cristológica, se refiere a la situación gloriosa permanente que revierte la experiencia dolorosa de la cruz; por otro, en una línea parenética, es puesto como objeto de la esperanza de los creyentes, la meta de la «carrera» y la motivación para la perseverancia.

31 Por ejemplo, Sal 36,12; 54,4; 118,61; 70,4; 96,10, etc. Cf. C. MARCheSELLI-CASALE, Lettera agli Ebrei, o. c., p. 555.

32 G. Mora, La carta a los Hebreos como escrito pastoral, o. c., p. 82. 


\section{El iniciador y perfeccionador de la fe, Jesús: aporte cristológico}

La frase que aplica a Jesús los títulos de iniciador y perfeccionador de la fe expresa sintéticamente la doctrina acerca de Cristo desarrollada a lo largo de la obra. La densidad de la expresión requiere una especial atención para percibir el alcance de sentido que el autor le confiere en el contexto no solo de la perícopa misma, sino en relación con lo expuesto en la totalidad del sermón.

Como un primer paso ofreceremos una apretada síntesis de la cristología de Heb que nos servirá de marco y de orientación, para luego confrontar esos elementos expuestos con el aporte cristológico de Heb 12,1-3, fundamentalmente condensado en el v. 2.

\subsection{Una aproximación a la cristología de $\mathbf{H e b}^{33}$}

Heb comienza con un prólogo en el que condensa admirablemente una elaborada cristología; allí se encuentra la preparación a toda la obra:

${ }^{1}$ Muchas veces y de muchos modos habló Dios en el pasado a nuestros padres por medio de los profetas; ${ }^{2}$ en estos últimos tiempos nos ha hablado por medio del Hijo, a quien instituyó heredero de todo, por quien también hizo los mundos; ${ }^{3}$ el cual, siendo resplandor de su gloria e impronta de su sustancia, y el que sostiene todo con su palabra poderosa, después de llevar a cabo la purificación de los pecados se sentó a la diestra de la majestad en las alturas, ${ }^{4}$ con una superioridad sobre los ángeles tanto mayor cuanto más les supera en el nombre que ha heredado ${ }^{34}$.

Se refiere a Jesús como «Hijo». Aquel por medio del cual Dios nos ha hablado $(1,1)$ y que ha llevado a plenitud la revelación iniciada desde antiguo. El Hijo alcanza aquí, como también en el prólogo de Juan, un puesto privilegiado como mediador de la revelación. Se diferencia de los

33 Para un desarrollo más extenso de este tema, cf. R. SCHNACKENBURG, «La cristología de la Carta a los Hebreos», en J. FEINER / M. LöHRER (eds.), Mysterium Salutis III: El acontecimiento de Cristo. Madrid, Cristiandad, 1980, pp. 291-296; A. VANHOYE, La cristología sacerdotal de la Carta a los Hebreos. Buenos Aires, Oficina del Libro de la CEA, 1997; L. RIVAS, «La cristología de la carta a los Hebreos. Jesucristo, único Salvador del mundo, ayer, hoy y siempre (cf. Heb 13,8)», en Revista Bíblica 65 (2003), pp. 81-114; P. HugHES, «The Christology of Hebrews», en Southwestern Journal of Theology 28 (1985), pp. 19-27; J. GNILKA, Teología del Nuevo Testamento. Madrid, Trotta, 1998, pp. 388-405.

${ }^{34}$ Heb 1,1-4. 
previos mediadores por los cuales habló Dios, que son los profetas, ya que nos habló por el Hijo en la plenitud de los tiempos. Es el revelador por excelencia porque es el resplandor de la gloria e impronta de la sustancia de Dios. Él ha sido establecido por Dios como heredero de todo, obteniendo así la soberanía universal (v. 2). Y no solo es mediador de la revelación, sino también de la creación: por medio de él, Dios creó el universo (v. 2c) y sigue sosteniendo todo con su palabra poderosa (v. 3a-b).

[El autor] ha explicado el contenido de la confesión de fe de los destinatarios recurriendo a conceptos tomados del mundo cultural y religioso del judaísmo alejandrino. El Hijo a través del cual Dios ha hablado lleva en sí mismo los rasgos de lo que Dios es, es coexistente con la eternidad de Dios, anterior a toda la creación, y por medio de él Dios realiza la obra de crear y conservar el universo ${ }^{35}$.

Se trata de una cristología cósmica, como la del himno de Col 1,15ss, estimulada por la especulación sobre la sabiduría, junto con las ideas de la preexistencia y la significación protológica del Hijo, que es imagen del ser de Dios, a la manera de lo que se dice en el prólogo del evangelio de Juan (Jn 1,1-3) ${ }^{36}$.

Enseguida menciona una acción propiamente sacerdotal: la purificación de los pecados obrada por el Hijo, que, si bien es solo una mención, ya anticipa desde el prólogo lo que será el tema central de la obra: el sacerdocio de Cristo. De la preexistencia del Logos pasa a su acción salvífica. Y de la pasión (sacrificio de purificación), sin explicitar la resurrección, pasa a la glorificación y entronización a la derecha de Dios, aludiendo por primera vez al Salmo 110. Finaliza el prólogo con una contemplación de la gloria de Cristo e introduciendo el tema de la primera parte: la superioridad del Hijo respecto de los ángeles. En estos pocos versículos demuestra que la Palabra de Dios y su acción están indisolublemente ligadas a la mediación de Cristo: es en él en donde Dios nos habla y nos salva ${ }^{37}$.

Dios viene en la persona de Jesucristo a compartir nuestra vida y a hablar no simplemente un lenguaje de palabras, sino también el lenguaje de una vida ofrecida y de una sangre derramada. Este es el efecto de la palabra de Dios. En Jesucristo se alcanza la plenitud en todos los aspectos: autoridad, revelación, evolución de la historia, y, sobre todo, el aspecto de la relación entre Dios y nosotros: Jesús es el mediador de una nueva alianza $(9,15)$, su sangre habla más elocuentemente que la de Abel $(12,24)^{38}$.

35 L. RIVAS, «La cristología de la carta a los Hebreos...», a. c., p. 92.

36 R. Schnackendurg, «La cristología de la Carta a los Hebreos», a. c., p. 292.

37 Cf. A. VAnhore, El mensaje de la carta a los Hebreos. Estella, Verbo Divino, 1978, p. 36.

38 A. Vanhoye, Our priest is Christ. The doctrine of the Epistle to the Hebrews. Roma, PIB, 1977, p. 17. 
Para destacar la superior dignidad del Hijo respecto de los ángeles, el autor utiliza una serie de citas del AT leídas en sentido mesiánico, aplicando a Jesús los títulos de Hijo, Primogénito, Señor y Dios, aunque el nombre de Jesús recién lo explicita por primera vez en 2,9b. En esta comparación, nuevamente el autor presenta el movimiento descendente y ascendente de humillación y gloria. Refiere el Salmo 8 a Jesús, que fue hecho «poco inferior a los ángeles», aunque «por poco tiempo», en alusión a su humanidad, pero luego de pasar por la experiencia de la muerte es coronado de gloria y honor. Después afirma que era necesario que el Hijo pade-

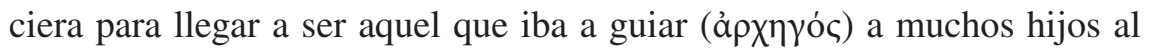
mismo objetivo, es decir, la salvación $(2,10)$.

Se introduce así el tema de la solidaridad de Jesús con los hombres, a quienes llama «hermanos» $(2,11)$ e «hijos» que Dios le ha dado $(2,13 \mathrm{~s})$. Para estar unido a ellos tomó la condición humana, participando de la carne y la sangre $(2,14)$. Y concluye: «Tuvo que hacerse en todo semejante a sus hermanos, para llegar a ser sumo sacerdote, misericordioso y digno de fe ante Dios, para expiar los pecados del pueblo» $(2,17)$. Por primera vez aplica el título de «Sumo Sacerdote» a Jesús luego de haber asegurado la solidaridad y simpatía con los hombres. Las características de ese Sumo Sacerdote es que es misericordioso y digno de fe, es decir, que posee los dos aspectos necesarios para ser un mediador perfecto: ser una sola cosa con Dios (lo cual ya estaba garantizado por ser Hijo) y ser una sola cosa con los hombres (verdadera humanidad, profunda solidaridad con la humanidad). Por tanto, el uso del título «Sumo Sacerdote» concentra dentro de sí la profundidad del concepto de una mediación perfecta y refleja las dos dimensiones de esa mediación:

La afirmación de la condición sacerdotal de Cristo es el punto en el que el autor de la carta ofrece mayor originalidad, ya que ni el vocabulario ni el tema aparecen explícitamente en otro escrito del Nuevo Testamento. Se puede decir que, en este aspecto, el tema obedece plenamente a su interpretación teológica de la muerte de Cristo $^{39}$.

La presentación sacerdotal [...] pone de relieve la necesidad que tiene el sumo sacerdote de mantener una doble relación muy estrecha con los hombres y con Dios. La pasión de Cristo se presenta como necesaria para establecer una solidaridad completa con los hombres: su glorificación celestial resulta necesaria para asegurar la relación perfecta con Dios. Los demás nombres no expresan más que algún que otro aspecto de la situación y del ser de Cristo. «Hijo de Dios» nos habla solamente de su relación con Dios; «hermano de los hombres» expresa solamente su relación con nosotros; «Señor» no evoca más que su gloria; «siervo» evoca solo su hu-

39 L. RIVAS, «La cristología de la carta a los Hebreos...», a. c., p. 95. 
millación voluntaria. Por el contrario, «Sumo Sacerdote» nos da la idea de su doble relación y recuerda al mismo tiempo la pasión y la gloria ${ }^{40}$.

Es Sumo Sacerdote fiel o digno de $\mathrm{fe}^{41}$ por estar acreditado ante Dios para presentar ante él la causa de los hombres. Es comparado con Moisés (3,2ss), por representar a Dios ante el pueblo y por su intimidad con él. Pero es superior a él porque Moisés era servidor de la casa y Jesús es hijo $(3,6)$ y constructor $(3,3)$. La glorificación del Hijo confirma su autoridad y su acreditación ante Dios y debe ser el estímulo que motiva a los creyentes a acercarse a él para entrar en el descanso prometido $(3,7-4,14)$.

Es Sumo Sacerdote misericordioso por su compasión hacia la miseria humana y su capacidad de abrir la miseria humana a la gracia victoriosa de Dios por medio de la oración y de la ofrenda a Dios; por su profunda solidaridad con los hombres en todo menos en el pecado; por compartir con los hombres las mismas pruebas, debilidades y flaquezas $(4,15 ; 5,2.8)$. La prueba más fuerte de esa solidaridad es la muerte $(2,9)$.

Junto con esas dos notas esenciales, el autor desarrolla tres nuevas características que distinguen el sacerdocio de Jesús respecto del sacerdocio antiguo, y cuya exposición constituirá el centro del sermón $(5,11$ 10,39) y el corazón de su cristología. Según la estructura de Heb propuesta por Vanhoye, dicha parte central $(7,1-10,18)$ se divide en tres secciones, correspondientes a cada una de esas características distintivas ${ }^{42}$.

La primera sección $(7,1-28)$ toma como base el oráculo de Sal 110,4: «El Señor lo ha jurado y no se arrepiente: Tú eres sacerdote eterno a la manera de Melquisedec», y así define cuál es el tipo de sacerdocio que corresponde a Cristo glorificado, un género distinto; no ya «según el orden de Aarón», sino «a la manera de Melquisedec» ${ }^{43}$. Es decir, no determinado por una genealogía terrena, sino por la filiación divina. Su institución pone en evidencia la imperfección del sacerdocio israelita, basado en una consa-

40 A. VAnhoye, El mensaje de la carta a los Hebreos, o. c., p. 38.

41 Cf. A. Vanhoye, Sacerdotes antiguos, sacerdote nuevo. Salamanca, Sígueme, 2002, pp. 108-112.

42 Cf. A. Vanhoye, L'epistola agli Ebrei, o. c., pp. 19-29.

43 «La misteriosa figura de Melquisedec ocupó la atención de otros autores de la época del Nuevo Testamento. Hay que recordar especialmente uno de los textos de Qumrán (11QMelch), en el que Melquisedec aparece como un personaje escatológico, que actuará para instaurar la salvación definitiva en relación con el texto del jubileo. En el Libro de los secretos de Enoc 23 (o II Enoc 71-73) se relata el milagroso nacimiento de Melquisedec (de madre virgen) y su traslado al paraíso para que sea eternamente el sacerdote de los sacerdotes», L. RIVAS, «La cristología de la carta a los Hebreos...», a. c., nota 57. 
gración ritual externa, incapaz de hacer perfecto ${ }^{44}$ a quien la reciba. De hecho, Cristo no pertenece a una familia sacerdotal ni se lo ve durante su vida ejerciendo el sacerdocio al modo israelita. Al aplicarle el título de «Sumo Sacerdote» era preciso establecer su origen para alcanzar el significado correcto del mismo. Además, mientras que en el AT se exigía solo la perfección de carácter ritual ${ }^{45}$ o la carencia de defectos corporales ${ }^{46}$, el Sumo Sacerdote del NT posee la santidad en todos los órdenes: es santo, inocente e inmaculado $(7,26)$, es decir, no comparte la solidaridad en el pecado, y por eso su sacrificio es agradable a Dios.

Cristo realmente ha sido «hecho perfecto para siempre» $(7,28)$ por su sacrificio. Este es el tema de la segunda sección $(8,1-9,28)$, que define el sacrificio de Cristo por medio de una confrontación con el culto de la alianza antigua. Esta tenía solamente «normas externas» $(9,10)$, ritos «carnales» ineficaces e incapaces de perfeccionar nada. Su santuario era terreno. Por el contrario, Cristo ha entrado en el verdadero santuario, es decir, «en el mismo cielo», gracias al ofrecimiento que hizo de sí mismo y que llevó a cabo una vez por todas ${ }^{47}$. De ese modo se ha convertido en «el mediador de la alianza nueva» anunciada por Jeremías ${ }^{48}$. Lo que el autor pone en juego es que la liturgia antigua era incapaz de establecer una mediación. El sacrificio de Cristo cambia la situación:

[El autor] afirma que «Cristo... a través de una tienda... y, por su sangre, entró en el santuario» $(9,11-12)$. En efecto, por su ofrenda a Dios es como la humanidad de Jesús ha quedado transformada. Lo que los antiguos sacrificios eran absolutamente incapaces de lograr (cf. 9,9) lo ha realizado esta ofrenda. Ella ha dado la «perfección» a Cristo (cf. 7,28; 5,9; 2,10), de forma que su humanidad es ahora «la tienda... más perfecta» que pone en relación con Dios. [...] Efectivamente, la ofrenda de Cristo a Dios ha consistido

44 «En la traducción griega del Antiguo Testamento, los ritos prescritos para conferir el sacerdocio no se llamaban "consagración sacerdotal" ni "ordenación", sino "perfeccionamiento" (teléiosis), esto es "acción que hace perfecto", “acción que da la perfección". Nuestro autor opina visiblemente que esta palabra está muy bien escogida, ya que una verdadera consagración sacerdotal tiene que transformar profundamente al que la recibe. De forma que en él ya no pueda disgustar nada a Dios. Es lo que exige su papel de mediador. Por tanto, la consagración sacerdotal tiene que dar la perfección", A. VANHOYE, El mensaje de la carta a los Hebreos, o. c., pp. 46-47.

45 Lv 21,1-15.

46 Lv 21,16-23.

47 A diferencia de los sumos sacerdotes antiguos, que cada año debían entrar en el santuario para ofrecer un sacrificio el Día de la Expiación, Cristo ofrece el sacrificio una vez y para siempre.

48 Jr 31,31-34; Heb 8,8-13. 
en un acto extremo de amor (cf. Jn 13,1; Heb 2,14-18; 4,15-16). No fue por él mismo, sino por nosotros, por lo que Cristo aceptó «aprender la obediencia por sus sufrimientos». Para sí mismo, Cristo no necesitaba esta transformación dolorosa; se sometió a ella «a pesar de ser Hijo» $(5,8)$. Aceptándola por nosotros, está en disposición de comunicárnosla. Si nos unimos a él en la fe, su sangre «purificará nuestras conciencias» y nos permitirá entonces «dar culto al Dios vivo» $(8,14)$. De esta manera, Cristo se ha convertido, como consecuencia de su pasión, en el «mediador de una alianza nueva» $(9,15)^{49}$.

La tercera sección (10,1-18) subraya la eficacia perfecta de la ofrenda personal de Cristo, que se comunica a los creyentes, en contraste con la impotencia de la ley antigua, la cual nunca podría procurar la purificación de las conciencias, a pesar de la repetición indefinida de las inmolaciones de animales. En efecto, «es imposible que la sangre de toros y machos cabríos quite los pecados» $(10,4)$; la ofrenda es eficaz porque no se ofrece algo externo, sino a sí mismo (10,5-7). Gracias al sacrificio y al sacerdocio de Cristo se ha transformado por completo la situación religiosa de los hombres. Cristo puso fin a esta situación sin salida, «porque por una ofrenda única ha hecho perfectos para siempre a aquellos que son santificados» $(10,14)$ :

[La afirmación de 10,14] tiene algo de sorprendente. Por una parte indica algo ya efectuado. Cristo ha hecho perfectos, eteleíōsen; el verbo griego indica una realidad ya comunicada. Por otro lado, la frase continúa indicando una realidad en devenir, un dinamismo: ha hecho perfectos a aquellos que son santificados, toùs hagiazoúmenos, aquellos que reciben ahora la santificación progresivamente; una acción en vía de desarrollo. Estos son dos aspectos de nuestra situación religiosa que se derivan de la oblación de Cristo. Por parte de Cristo ya ha sido todo realizado. Él nos ha hecho perfectos. Por la nuestra, todo está en vías de realización ${ }^{50}$.

Así, en el desarrollo de la doctrina del sumo sacerdocio de Jesús se conjugan, junto con la cristología, una novedosa soteriología y escatología. Por este ejercicio sacerdotal, los hombres pueden participar de la salvación de Dios y «entrar en el santuario», es decir, llegar a la meta, a la perfección, al $\tau \dot{\varepsilon} \lambda o \varsigma$. No hay otro camino para la salvación que este:

Tenemos, pues, hermanos, plena seguridad para entrar en el santuario en virtud de la sangre de Jesús, por este camino nuevo y vivo, inaugurado por él para nosotros, a través del velo, es decir, de su propia carne (Heb 10,19-20).

A estas palabras sigue la invitación a acercarse $(10,22)$. Lo que se celebra es, pues, el camino abierto por Cristo. Él lo ha abierto por su sangre y por

49 A. Vanhoye, El mensaje de la carta a los Hebreos, o. c., pp. 50-52.

50 A. Vanhore, Recibamos a Cristo, nuestro sumo sacerdote. Buenos Aires, Agape, 2009, p. 130. 
su carne, en virtud del sacrificio de su muerte. Esta idea encaja perfectamente con la concepción soteriológica de la carta. Nada indica que Cristo en su entrada haya dejado su carne en el muro que separa el mundo de Dios del de los hombres. En su carne, en su condición humana, Cristo confirmó su solidaridad con nosotros, los hombres; confirmó que es un Sumo Sacerdote compasivo y fiel. Y sigue siéndolo. En su condición de tal se presentó ahora ante el trono de Dios para interceder en favor nuestro $(9,24)$. En cuanto tal sigue intercediendo para siempre por nosotros $(7,25)$. Su actividad permanente de Sumo Sacerdote consiste en esa intercesión compasiva y fiel, no en un culto celeste que continuara la muerte en la $\mathrm{cruz}^{51}$.

Los medios para realizar la unión de los hombres con Cristo y participar así de los frutos de su sacrificio serán la fe y la paciencia (10,36-39), desarrollados ampliamente en las dos últimas partes de Heb. De modo que el hombre ya desde ahora puede participar del fin y de la meta, aunque todavía de un modo parcial y «en proceso». Sintetiza la doctrina del «ya, pero todavía no» acuñada luego en la teología, mostrando la positiva tensión inaugurada con el sacrificio de Cristo:

La soteriología, que gira toda ella en torno a Jesús, ha acuñado la escatología; por ello también esta tiene una impronta cultual. Heb subraya el «ya» de la purificación de nuestro pecado, y con ello de la de nuestra entrada en el santuario celeste de Dios; solamente a partir de ella se entiende nuestra $\sigma \omega \tau \eta \rho i a$ definitiva, no como gracia exclusivamente futura, sino como la realización acabada del don escatológico ya incoadamente recibido ${ }^{52}$.

\subsection{Nuestro pasaje puesto en relación con la cristología de toda la carta a los Hebreos}

Habiendo presentado ya una breve síntesis de la doctrina cristológica de Heb, y algunas notas de su soteriología y escatología, daremos cuenta ahora de la originalidad y de las relaciones de nuestra perícopa con lo ya expuesto.

Varios autores han coincidido en que la frase de Heb 12,2, que aplica a Jesús los títulos de iniciador y perfeccionador de la fe, de algún modo resume la honda cristología de Heb. Así, por ejemplo, B. Lindars, en un breve párrafo, expresa esta constatación:

Todo podría ser resumido muy simplemente con la doble definición de Jesús, «el pionero y perfeccionador de nuestra fe». Aquí está concentrada la esencia de la teología de la carta a los Hebreos sin renunciar a su expresión

51 J. GNILKa, Teología del Nuevo Testamento, o. c., p. 405.

52 G. Mora, La carta a los Hebreos como escrito pastoral, o. c., p. 222. 
práctica, tan importante para el autor. Jesús es el pionero porque es hombre y ha recorrido el camino que cada uno debe transitar, permaneciendo fiel en el momento de la tentación y ofreciendo su voluntad a Dios hasta la muerte. Este es el camino que se les propone a los lectores y que es un aspecto de la respuesta de nuestra fe. Jesús es también el perfeccionador porque, en cuanto agente de la voluntad preestablecida por Dios de llevar a cumplimiento la salvación (1,1-4), primero ha completado en sí mismo el proceso mediante su muerte y exaltación a la derecha de Dios, haciéndolo accesible a aquellos que confiesan su nombre. También ellos completarán el proceso salvífico si mantienen la fe, que es la respuesta activa a la certeza dada desde la inauguración de la nueva alianza ${ }^{53}$.

También G. Mora coincide en la misma afirmación:

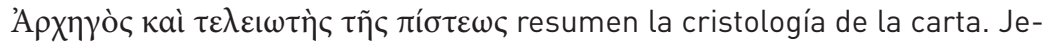
sús, a quien debemos contemplar, es nuestro hermano, igual en todo a nosotros, que por su fidelidad entra en el santuario y al mismo tiempo nos abre su camino dándonos con ello el don escatológico de Dios. Precisamente por eso puede ser nuestro modelo; su camino hacia la perfección, que le constituyó como sacerdote salvador nuestro, no fue un proceso ritual, sino totalmente personal-existencial de obediencia a través de los sufrimientos. En ellos, el Hijo fue probado, pero aceptó totalmente el plan salvífico de Dios, recibiendo por su fortaleza constante la glorificación eterna. De ahí que 12,2 anuncie concisamente el resumen de todo este proceso salvífico personal, en el cual se apoya el uso parenético de la pasión de Jesús como ejemplo nuestro ${ }^{54}$.

Asimismo, nosotros hacemos propia esta opinión y en este apartado trataremos de desarrollar los motivos que nos conducen a ella.

Son necesarias dos previas aclaraciones referentes a los títulos

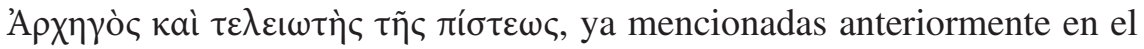

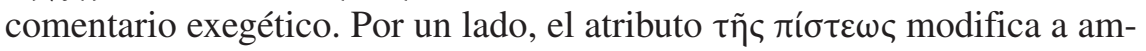

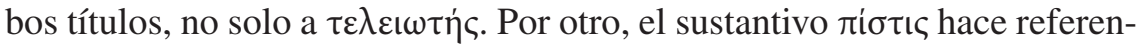
cia no a la fe de Jesús, sino a la de los creyentes ${ }^{55}$.

El título ả $\rho\rceil \gamma \gamma o ́ \varsigma$, ya utilizado en 2,10 , puede ser traducido tanto en el sentido de «pionero» (es decir, como el primero en iniciar un camino que él mismo ha recorrido) o como «autor» o «iniciador» (en el sentido de «aquel que da origen»). Envuelve esa riqueza de significado que, en nuestra perícopa, es más legítimo entenderlo del segundo modo, ya que la fe no

53 B. Lindars, Teologia della lettera agli Ebrei. Brescia, Paideia, 1993, p. 164.

54 G. Mora, La carta a los Hebreos como escrito pastoral, o. c., pp. 177-178.

55 Cf. F. MANZI, «La fede degli uomini e la singolare relazione filiale di Gesù con Dio nell'Epistola agli Ebrei», en Biblica 81 (2000), p. 52; A. VANHOYE, «La fede di Gesù?...», a. c., p. 414. 
puede ser atribuida a Jesús del mismo modo que a un creyente ${ }^{56}$. Sin embargo, el término deja abierta la posibilidad de referirse también a la verdadera humanidad de Jesús, compartida en todo con nosotros menos en el pecado, especialmente aludiendo a la experiencia de su obediencia filial:

El hecho de que Jesús no sea una simple persona humana, sino una persona divina, «el Hijo de Dios» (Heb 4,14), «Dios» con Dios (1,8.9), tiene como resultado que su relación personal con Dios no pueda ser una simple relación de fe. Pero conviene observar que se refiere al nivel más alto de la fe, la cual comprende también otros niveles, como aquellos que están comprendidos en la definición de Heb 11,1. En estos otros niveles, Jesús, a causa de su naturaleza humana de «sangre y carne» $(2,14)$, compartía nuestra situación y ha sido un «pionero de la fe», como lo atestiguan sus oraciones suplicantes «a aquel que podía salvarlo de la muerte» ${ }^{57}$.

Así, Jesús es presentado en su profunda igualdad con nosotros, pero a la vez en radical diferencia por su condición de Hijo (misericordioso y digno de fe). Su función única y exclusiva como iniciador se refiere a suscitar la fe en los creyentes en orden a hacerlos capaces de imitarlo, no en su

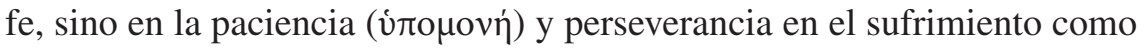

56 No obstante esta aclaración, la cuestión permanece abierta. Desde el punto de vista exegético, el problema no es fácil. Algunos autores, como Wescott, Delling o Gräser, se inclinan por atribuir la fe también a Jesús; otros, como Teodorico y Spicq, excluyen esta interpretación. Es cierto que en el NT jamás se dice que Jesús haya creído en Dios. Su relación con el Padre era de un orden diverso, un conocimiento diverso, inmediato, no un conocimiento por medio de la fe recibida (Mt 11,27). Propongo la solución de A. VANHoYe, L'epistola agli Ebrei, o. c., p. 270: «En el nivel más profundo de su conciencia humana no había lugar, en Jesús, para una relación de fe teologal con Dios. Pero una conciencia humana tiene muchos otros niveles, y es posible retener que en estos niveles Jesús se hallase en una situación análoga a aquella de los simples creyentes, porque no se mostraba en una situación de Hijo de Dios; sino que era en todo semejante a los hermanos $(2,17 ; 4,15)$, lo que significa "en una condición de esclavo" (Flp 2,7) y no de hijo; aún peor, "en una carne semejante a la carne de pecado" (Rom 8,3). En estos niveles él podía entonces probar y vivir todo aquello que prueban y viven los creyentes. Cuando "ha ofrecido súplicas y oraciones a aquel que podía salvarlo de la muerte" (5,7), él se encontraba en una situación de oscuridad y angustia. Los evangelios muestran que él no sabía si era posible que el Padre apartase o no el cáliz de la pasión; su conciencia de Hijo continuaba igualmente confirmándose, porque decía: "Padre, no se haga como yo quiero, sino como quieres tú" (Mt 26,39). Su confianza en el Padre era total, como también su docilidad, llena de “humilde sumisión” (eulabeia, 5,7). Su fidelidad permaneció inmutable a pesar de las terribles pruebas [...]. Confianza en Dios, docilidad, humilde sumisión, fidelidad: todas estas actitudes están en estrecha relación con la fe. Jesús ha sido el ejemplo perfecto. En este sentido es "aquel que da origen a la fe y la lleva a cumplimiento" (12,2)».

57 A. VANHOYE, «La fede di Gesù?...», a. c., p. 415. 
prueba de obediencia filial. En este orden de interpretación se inscribe también santo Tomás de Aquino en su comentario a Heb: «Si quieres, pues, salvarte, pon los ojos en el rostro de tu Cristo, que es autor de la fe por dos razones: porque la enseña de palabra (Heb 1,2 ; Jn 1,18$)$ y porque la imprime en los corazones $\left(\right.$ Flp 1,29)» ${ }^{58}$.

En cuanto a $\tau \varepsilon \lambda \varepsilon เ o \tau \eta ́ c$, la referencia al eje sacerdotal de Heb es mucho más directa y clara. Como hemos demostrado, la parte central del sermón $(8,1-9,28)$ tiene este tema como su punto capital. Por un lado, Jesús es llevado a la perfección ( $\tau \varepsilon \lambda \varepsilon ı 0 \theta \varepsilon i \varsigma)$ por el Padre a través del sufrimiento y la obediencia, encontrándose en su sacrificio la consumación de su sumo sacerdocio $(2,10 ; 5,9 ; 7,28)$; y, por otro, él mismo como Sumo sacerdote es

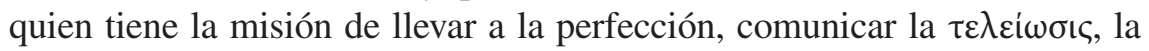
salvación y la consumación escatológica $(9,10 ; 10,1 ; 10,14)^{59}$. Vanhoye sostiene que la $\tau \varepsilon \lambda \varepsilon i \omega \sigma ı \varsigma$ de Cristo es el punto capital de toda la cristología de Heb, y que manifiesta dos características: existencial y relacional. Existencial, lograda por enfrentar las duras realidades de la existencia humana. Relacional, obtenida al unir estrechamente dos relaciones que parecían ser mutuamente excluyentes: la relación de perfecta obediencia a Dios y la de la solidaridad con los pecadores. Por tanto, la $\tau \varepsilon \lambda \varepsilon i \omega \sigma \iota \varsigma$ sacerdotal de Cristo lo constituye en el «mediador de una nueva alianza» $(9,15)$. Lo constituye en el sacerdote «misericordioso y digno de fe» que necesitábamos $(\mathrm{Heb} 2,17)^{60}$.

Por otro lado, como ya hemos observado, hay una estrecha correspondencia entre esta confesión de fe de 12,2 y la de 2,10. Una comparación

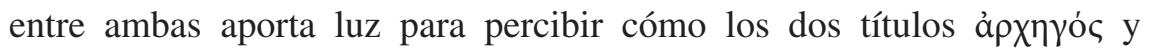

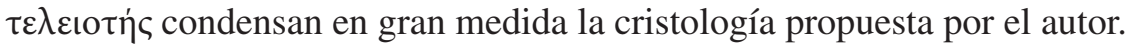

El nexo entre 12,2 y 2,10 aparece todavía más estrecho con motivo de la con-

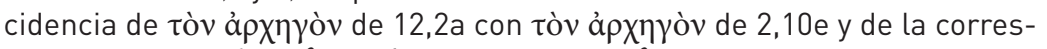

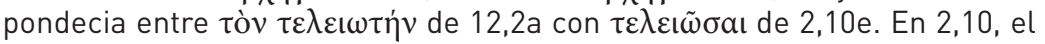
camino que lleva la «salvación de los hombres» ( $\tau \tilde{\eta} \varsigma \sigma \omega \tau \varepsilon \rho i a \varsigma ~ a u ̉ \tau \tilde{\omega} v$ ) ha sido abierto en virtud de la mediación de Cristo, el cual, como «pionero» (ả $\rho \chi \eta \gamma o ́ \varsigma)$ y «precursor» ( $\pi \rho o ́ \delta \rho o \mu o \varsigma, 6,20 a)$, ha sido elevado a lo más alto de los cielos $(7,26$ d; cf. 4,14$)$ y ha entrado en el Santo de los Santos del cielo $(6,19-20)$. Análogamente para 12,2, Cristo es el «pionero» que, estando «sentado a la derecha del trono de Dios» (v. 2e), ha hecho soteriológica-

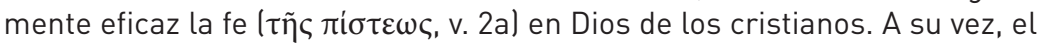

58 Santo Tomás de Aquino, Super epistolam B. Pauli ad hebraeos lectura I, 1 (Textum Taurini 1953 editum], en http://www.corpusthomisticum.org/che01.html [consultado el 13 de octubre de 2012].

59 Cf. G. Mora, La carta a los Hebreos como escrito pastoral, o. c., p. 177.

60 A. VANHOYE, «La teleiôsis du Christ: point capital de la Christologie sacerdotale d'Hébreux», en New Testament Studies 42 (1996), p. 338. 
título $\tau \varepsilon \lambda \varepsilon$ เo («acto de investidura sacerdotal») y existencial («perfeccionamiento» personal)- del verbo $\tau \varepsilon \lambda \varepsilon เ o \tilde{v} v$ de 2,10e. [...] En este sentido, [esta interpretación encuentra fundamento] en 10,14, según la cual, «por medio de una sola ofrenda» Jesús ha conferido el perfeccionamiento ( $\tau \varepsilon \tau \varepsilon \lambda \varepsilon i ́ \omega \kappa \varepsilon v$ ) para siempre a aquellos que son santificados ${ }^{61}$.

La relación con el sacrificio de Cristo se hace más directa con la introducción de la homología de $2 \mathrm{~b}$, donde nuevamente queda de manifiesto el proceso de humillación-exaltación soportado por Cristo. Es mencionado el acontecimiento de la cruz, no en un sentido figurado, sino histórico. La opción por el sufrimiento frente al gozo, el desprecio de la ignominia y la paciencia al soportar la cruz remiten al tema de la $\tau \varepsilon \lambda \varepsilon i \omega \sigma ı \varsigma ~ a l c a n z a d a$ por medio del padecimiento (5,7-9). Por su parte, la entronización a la derecha $(12,2)$ remite perfectamente al prólogo, en el que, luego de hablar de la prexistencia del Hijo, cita también el Sal 110,4 como consecuencia del sacrificio de purificación de los pecados (movimiento descendenteascendente). Tanto su sufrimiento humano como su exaltación celestial hablan del sumo sacerdote que ha llevado a cabo el sacrificio supremo, que nos ha purificado del pecado, que ha pasado por el velo a la presencia de Dios, donde intercede por nosotros y hace posible para nosotros acceder libremente al trono de la gracia ${ }^{62}$.

Así pues, en esta cristología sacerdotal en la que Jesús, caudillo de la salvación, ha alcanzado ya la meta celeste escatológica, la parusía queda como en segundo plano en cuanto revelación de la gloria de Cristo; no obstante, sigue vigente la tensión escatológica entre la posesión de la salvación y su espera, entre la promesa y la plenitud de la salvación ${ }^{63}$.

Finalmente, es preciso volver a enmarcar el versículo en el contexto la perícopa 12,1-13. El carácter es netamente exhortativo. De modo que la breve y condensada exposición cristológica del v. 2 se circunscribe en la parénesis que busca presentar el ejemplo de Cristo como estímulo para los creyentes. Evidentemente, no se trata solo de una actitud de imitación, sino de la toma de conciencia de una nueva realidad de la que ya el creyente es partícipe por el camino abierto por Jesús. La vivaz indicación a desprenderse del pecado $(12,1.4)$ demuestra que la situación ha dado un giro. La posibilidad de desprendernos del pecado, de ser purificados, pertenece a los

${ }_{61}$ F. MANZI, «La fede degli uomini e la singolare relazione filiale di Gesù con Dio nell'Epistola agli Ebrei», a. c., p. 53.

${ }^{62}$ E. Horning, «Chiasmus, creedal structure, and christology in Hebrews 12:12», a. c., p. 46.

63 R. Schnackenburg, «La cristología de la Carta a los Hebreos», a. c., p. 296. 
últimos tiempos. Solo en virtud del único sacrificio eficaz de Jesucristo puede ser purificada la conciencia del pecado y es posible acceder al santuario para dar culto a Dios. Así, el creyente fue arrancado del antiguo sistema ineficaz e incapaz de perdonar los pecados $(10,4)$ y fue introducido en el santuario del cielo, cuya puerta fue abierta por Cristo $(9,12.24 ; 10,19)$. Sin embargo, a pesar de esta purificación es preciso mantener la lucha y la constancia hasta el final. De ahí que el ejemplo de Jesús en su vida mortal sea para el creyente el espejo en el que mirar y aprender la actitud necesaria

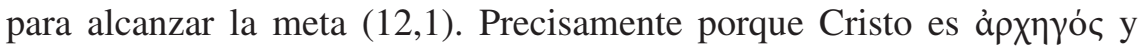

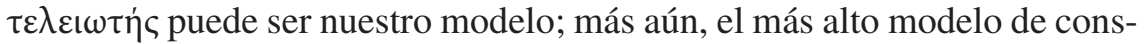
tancia, de paciencia y de obediencia expresados en el sacrificio de su vida. Así su ejemplo será el único estímulo válido para no decaer en la carrera $(12,3.5 .7)$ y su actitud filial será la realización más perfecta de la $\pi \alpha ı \delta \varepsilon i ́ a$ que el Padre obra en sus hijos (12,5-11).

\section{Conclusión}

Jesús es el autor y perfeccionador de la fe porque con el sufrimiento

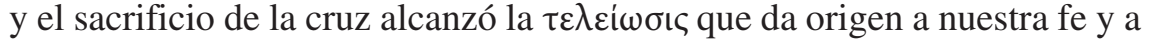
su vez la lleva a participar de esa misma perfección. Esta es la verdad fundamental que condensa, en gran parte, lo que el autor expone en los capítulos precedentes. La cruz nos permite correr la carrera de la fe, nos da la capacidad (que antes no teníamos) de llegar a la meta prometida, de entrar en «el santuario», de participar de la vida y la santidad de Dios. El modo en cómo tenemos que correr esa carrera nos lo revela él mismo con su ejemplo: la paciencia en el sufrimiento, el soportar con constancia la prueba, el despreciar la ignominia con vistas a conseguir la gloria. Él, siendo Hijo, tuvo que padecer. Los creyentes, que también somos hijos, aunque de

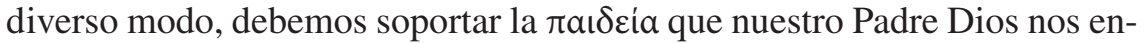
vía como prueba de su amor, sabiendo que por medio ella, si la aceptamos como Jesús, recorremos la senda que ha sido abierta por él y que nos conduce a la salvación.

Nicolás PEDRo Guidi 